\title{
Erratum
}

Orthopäde 2016 • 45:91-92

DOI 10.1007/s00132-015-3209-6

Online publiziert: 18. Dezember 2015

(c) Springer-Verlag Berlin Heidelberg 2015

CrossMark

Erratum zu:

Orthopäde (2015)

44:917-926

DOI 10.1007/s00132-015-3181-1

Leider wurden in $\bullet$ Tab. 1 zum Teil falsche Angaben gemacht. Bitte beachten Sie die folgende korrekte Tabelle:

Wir bitten diesen Fehler zu entschuldigen.

Die Redaktion
A. Kolb $\cdot$ R. Windhager - C. Chiari

Univ. Klinik für Orthopädie, Medizinische Universität Wien, Wien, Österreich

\section{Erratum zu: Kongenitale Hüftdysplasie, Screening und Therapie}

\section{Korrespondenzadresse}

\section{Dr. A. Kolb}

Univ. Klinik für Orthopädie, Medizinische Universität Wien

Spitalgasse 23, 1090 Wien

alexander.kolb@meduniwien.ac.at

Die Online-Version des Originalartikels ist unter doi:10.1007/s00132-015-3181-1 zu finden.

\section{Tab. 1 Einteilung der Hüfttypen nach Graf}

\begin{tabular}{|c|c|c|c|c|}
\hline Typ & Beschreibung & a-Winkel & $\beta$-Winkel & Maßnahmen und Therapie \\
\hline \multicolumn{5}{|c|}{ Typ I - Normal entwickelte und ausgereifte Hüfte } \\
\hline la & $\begin{array}{l}\text { Jedes Lebensalter } \\
\text { Normal entwickelte Hüfte. } \\
\text { Knöcherner Erker eckig/stumpf }\end{array}$ & $\begin{array}{l}\geq 60^{\circ} \\
\text { Knöcherne Formgebung } \\
\text { gut }\end{array}$ & $\begin{array}{l}<55^{\circ} \\
\text { Knorpeliges Pfannendach } \\
\text { übergreifend }\end{array}$ & Keine Therapie \\
\hline $\mathrm{lb}$ & $\begin{array}{l}\text { Jedes Lebensalter } \\
\text { Normal entwickelte Hüfte } \\
\text { Knöcherner Erker eckig/stumpf }\end{array}$ & $\begin{array}{l}\geq 60^{\circ} \\
\text { Knöcherne Formgebung } \\
\text { gut }\end{array}$ & $\begin{array}{l}>55^{\circ} \\
\text { Knorpeliges Pfannendach } \\
\text { übergreifend }\end{array}$ & Keine Therapie \\
\hline \multicolumn{5}{|c|}{ Typ II - Reifungsverzögerung der Hüfte (Dysplasie) } \\
\hline Ila (+) & $\begin{array}{l}\text { Bis 3. Lebensmonat } \\
\text { Physiologische Verzögerung der } \\
\text { Hüftentwicklung } \\
\text { Knöcherner Erker rund }\end{array}$ & $\begin{array}{l}50^{\circ}-59^{\circ} \\
\text { Knöcherne Formgebung } \\
\text { ausreichend }\end{array}$ & $\begin{array}{l}>55^{\circ} \\
\text { Knorpeliges Pfannendach } \\
\text { übergreifend }\end{array}$ & Keine Therapie, aber Kontrolle notwendig \\
\hline Ila (-) & $\begin{array}{l}\text { Bis 3. Lebensmonat } \\
\text { Physiologische Verzögerung } \\
\text { der Hüftentwicklung mit } \\
\text { Reifungsdefizit der Knochen } \\
\text { Knöcherner Erker rund }\end{array}$ & $\begin{array}{l}50^{\circ}-59^{\circ} \\
\text { Knöcherne Formgebung } \\
\text { mangelhaft }\end{array}$ & $\begin{array}{l}>55^{\circ} \\
\text { Knorpeliges Pfannendach } \\
\text { übergreifend }\end{array}$ & $\begin{array}{l}\text { Kontrolle in kurzem zeitlichem Abstand. } \\
\text { Spreizbehandlung }\end{array}$ \\
\hline $\mathrm{llb}$ & $\begin{array}{l}\text { Nach 3. Lebensmonat } \\
\text { Echte Reifungsverzögerung } \\
\text { (verzögerte Knochenreifung) } \\
\text { Knöcherner Erker rund }\end{array}$ & $\begin{array}{l}50^{\circ}-59^{\circ} \\
\text { Knöcherne Formgebung } \\
\text { mangelhaft }\end{array}$ & $\begin{array}{l}55^{\circ}-70^{\circ} \\
\text { Knorpeliges Pfannendach } \\
\text { übergreifend }\end{array}$ & Spreizbehandlung erforderlich \\
\hline IIc & $\begin{array}{l}\text { Gefährdete oder kritische Hüfte } \\
\text { Hüfte ist luxierbar } \\
\text { Knöcherner Erker rund bis flach }\end{array}$ & $\begin{array}{l}43^{\circ}-49^{\circ} \\
\text { Knöcherne Formgebung } \\
\text { hochgradig mangelhaft }\end{array}$ & $\begin{array}{l}<77^{\circ} \\
\text { Knorpeliges Pfannendach } \\
\text { noch übergreifend }\end{array}$ & $\begin{array}{l}\text { Sofortige Spreizbehandlung } \\
\text { Ohne Behandlung verschlechtert sich die } \\
\text { Dysplasie }\end{array}$ \\
\hline $\mathrm{D}(\mathrm{Ild})$ & $\begin{array}{l}\text { Hüfte beginnt zu dezentrieren } \\
\text { Knöcherner Erker rund bis flach }\end{array}$ & $\begin{array}{l}43^{\circ}-49^{\circ} \\
\text { Knöcherne Formgebung } \\
\text { hochgradig mangelhaft }\end{array}$ & $\begin{array}{l}>77^{\circ} \\
\text { Knorpeliges Pfannendach } \\
\text { verdrängt }\end{array}$ & $\begin{array}{l}\text { Sofortige Spreizbehandlung Sichere Im- } \\
\text { mobilisation (bspw. Spreizgips) erforderlich }\end{array}$ \\
\hline
\end{tabular}




\section{Erratum}

\section{Tab. 1 Fortsetzung}

\begin{tabular}{|c|c|c|c|c|}
\hline Typ & Beschreibung & a-Winkel & $\beta$-Winkel & Maßnahmen und Therapie \\
\hline \multicolumn{5}{|c|}{ Typ III - Dezentrierte Hüftgelenke (Dysplasie mit Fehlstellung) } \\
\hline Illa & $\begin{array}{l}\text { Dezentriertes Gelenk } \\
\text { Knöcherner Erker flach }\end{array}$ & $\begin{array}{l}<43^{\circ} \\
\text { Knöcherne Formgebung } \\
\text { schlecht }\end{array}$ & $\begin{array}{l}>77^{\circ} \\
\text { Knorpeliges Pfannendach } \\
\text { verdrängt ohne Struktur- } \\
\text { störung }\end{array}$ & $\begin{array}{l}\text { Sofortige Behandlung zwingend } \\
\text { Eventuell stationäre Aufnahme in ein } \\
\text { Krankenhaus } \\
\text { Korrektur der Hüftposition } \\
\text { Immobilisation mit Gips }\end{array}$ \\
\hline $\mathrm{IIllb}$ & $\begin{array}{l}\text { Dezentriertes Gelenk } \\
\text { Knöcherner Erker flach }\end{array}$ & $\begin{array}{l}<43^{\circ} \\
\text { Knöcherne Formgebung } \\
\text { schlecht }\end{array}$ & $\begin{array}{l}>77^{\circ} \\
\text { Knorpeliges Pfannendach } \\
\text { verdrängt mit Struktur- } \\
\text { störung }\end{array}$ & $\begin{array}{l}\text { Sofortige Behandlung zwingend } \\
\text { Stationäre Aufnahme in ein Krankenhaus } \\
\text { Korrektur der Hüftposition } \\
\text { Immobilisation mit Gips }\end{array}$ \\
\hline \multicolumn{5}{|c|}{ Typ IV - Vollständige Hüftluxation (schwere Dysplasie mit starker Fehlstellung) } \\
\hline IV & Vollständige Luxation & $\begin{array}{l}<43^{\circ} \\
\text { Knöcherne Formgebung } \\
\text { schlecht }\end{array}$ & $\begin{array}{l}>77^{\circ} \\
\text { Knorpeliges Pfannendach } \\
\text { nach mediokaudal verdrängt }\end{array}$ & $\begin{array}{l}\text { Sofortige Behandlung zwingend } \\
\text { Stationäre Aufnahme in ein Krankenhaus } \\
\text { Korrektur der Hüftposition } \\
\text { Immobilisation mit Gips }\end{array}$ \\
\hline
\end{tabular}


Hier steht eine Anzeige.

国pringer 